\title{
Leitura comunitária do futuro loteamento Canaã: senso de comunidade, expectativas e prioridades
}

The future allotment Canaã community reading: community sense, expectations and priorities

\section{Lecture communautaire du futur lotissement Canaã: sens de communauté, attentes et priorités}

\author{
Lectura comunitaria del futuro loteamiento Canaã: sentido de comunidad, expectativas \\ $y$ prioridades
}

\author{
Andréa Quadrado Mussi*
}

Recebido em 28/03/2016; revisado e aprovado em 23/08/2016; aceito em 27/09/2016

DOI: http:/ / dx.doi.org/10.20435/1984-042X-2016-v.17-n.4(05)

\begin{abstract}
Resumo: A pesquisa buscou reforçar o vínculo comunitário e sistematizar as percepções e expectativas das futuras 210 famílias moradoras do loteamento Canaã, em Passo Fundo, RS, Brasil, quanto ao espaço urbano compartilhado. Foram aplicadas três dinâmicas de participação comunitária visando projeto colaborativo. O mais apontado foi segurança, tranquilidade, companheirismo e espaços de playground e áreas verdes. Estas técnicas aproximam as pessoas e aumentam o vínculo.
\end{abstract}

Palavras-chave: planejamento habitacional; loteamento de interesse social; interesse coletivo.

Abstract: The research sought to strengthen the community bond and to systematize the perceptions and expectations of the 210 future families local residents at the Canaã allotment, in Passo Fundo, Brazil, of them for the shared urban space. We applied three dynamics of community participation aimed at collaborative project. Where the most pointed was security, peace, fellowship and spaces of playground and green areas. These techniques bring people together and increasing the bond. Key words: housing planning; low income allotment; coletive interest.

Résumé: La recherche a visé le renforcement des liens communautaires et la sistématization des perceptions et attentes des 210 familles futures habitantes du Lotissement Canaã, à Passo Fundo, RS, Brésil, en ce qui concerne l'espace urbain partagé. Trois dynamiques de groupe ont été realisées comme moyen d'obtention d'un projet collaboratif. Parmis les critéres les plus mentionnés se trouvent la sécurité, tranquilité, les espaces de recréation et espaces vertes. Ces téchniques approchent les personnes et renforcent ses liens sociales.

Mots-clés: planification habitational; logement d'interet social; interet collectif.

Resumen: La investigación buscó fortalecer el vínculo comunitario y sistematizar las percepciones y expectativas de las futuras 210 familias residentes del loteamiento Canaã, en Passo Fundo, RS, Brasil, cuanto al espacio urbano compartido. Aplicamos tres dinámicas de participación comunitaria con el objetivo de proyecto colaborativo. El más apuntado como deseo para el loteamiento fue seguridad, tranquilidade, compañerismo y a los espacios de parque infantil y áreas verdes. Estos técnicas acercan a las personas y aumento del vínculo.

Palabras clave: planificación de vivenda; loteamiento de interés social; interés colectivo.

\section{INTRODUÇÃO}

A importância de estabelecer vínculos com os vizinhos e a comunidade que faz parte de uma porção da cidade é primordial para o alcance de objetivos comuns com maior agilidade e perenidade. Verificar as expectativas comuns quanto ao espaço urbano compartilhado é construir uma leitura comunitária do local que favorecerá a convivência e o desenvolvimento sadio desse espaço (CILLIERS; TIMMERMANS, 2014).

Este artigo apresenta a descrição da metodologia de empoderamento aplicada na leitura comunitária do futuro

* Faculdade Meridional (IMED), Passo Fundo, Rio Grande do Sul, Brasil.

INTERAÇÕES, Campo Grande, MS, v. 17, n. 4, p. 607-620, out./dez. 2016. 
loteamento Canaã, uma das etapas de um conjunto de atividades de pesquisa e extensão desenvolvidas pela Instituição de Ensino Superior (IES) Faculdade Meridional (IMED) com a entidade Grupo de Mulheres Unidos Venceremos, desde 2011, mediante convênio de ensino, pesquisa e extensão.

A temática abordada no artigo está em enquadrar a experiência de parceria entre a IES e essa entidade na implantação de um loteamento de interesse social autogerido (Loteamento Canaã, Passo Fundo, RS, Brasil), dentro do campo do urbanismo contemporâneo ${ }^{1}$, em especial no âmbito de ações do tipo bottom-up ${ }^{2}$. Ressalta, assim, a importância do empoderamento comunitário para o êxito de intervenções urbanas na cidade.
Há um "distanciamento entre discurso e prática" nas pesquisas sobre habitação no Brasil (MARICATO, 2009, p. 33). O discurso do urbanismo contemporâneo, reproduzido no campo legislativo brasileiro pelo Estatuto da Cidade, é abordado, aqui, a partir da relação estabelecida entre suas diretrizes, seus instrumentos de regulação do solo e de provisão habitacional e a experiência retratada, mediante uma categorização conceitual (Figura 1). Essa categorização busca destacar uma possível aproximação entre a prática do urbanismo contemporâneo (objeto empírico apresentado) e o discurso. Como o caso examinado demonstra, o somatório das ações compreendidas em cada uma das áreas destacadas completa e exemplifica um ciclo do urbanismo contemporâneo ${ }^{3}$.

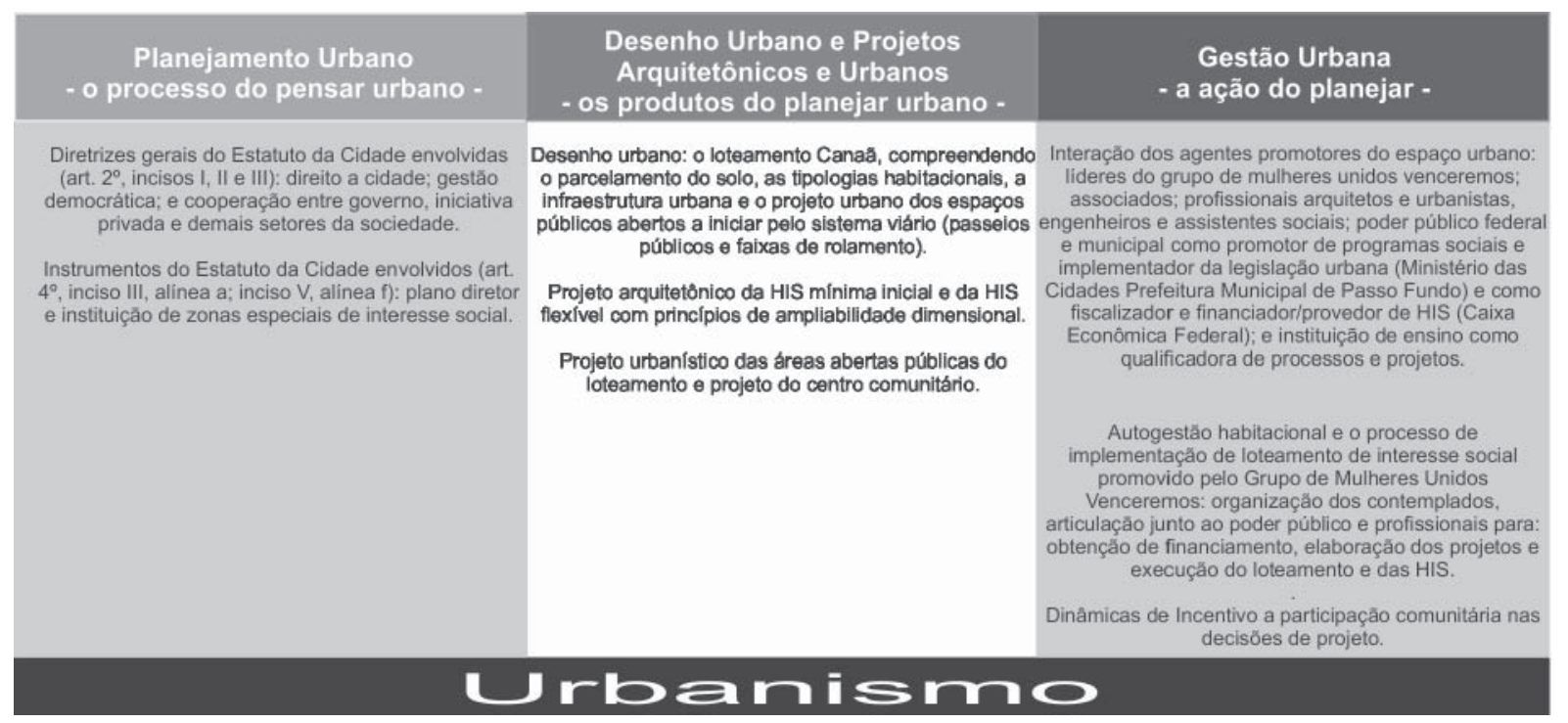

Figura 1 - Esquema da relação das ações para implementação do loteamento Canaã com termos conceituais da área do urbanismo

\footnotetext{
${ }^{1}$ A participação comunitária com a inclusão de todos os agentes sociais na construção da cidade contemporânea são princípios compartilhados pelos movimentos Smart Growth e o New Urbanism (KATZ, 1994; MAWROMATIS, 2013).

${ }^{2}$ A ação deve tomar partido da vontade da população de mudar. Deve ser um processo que funciona de baixo para cima, isto é, a partir da base: da população para o topo, o governo.
}

\footnotetext{
${ }^{3}$ Os termos que caracterizam as facetas do urbanismo contemporâneo, como planejamento urbano e regional, planejamento estratégico, desenho urbano e projetos urbanos, advêm "de variações temporais da concepção de urbanismo" (NOVAK, 2006, p. 141), influenciados pela revolução industrial.
} 
Os principais objetivos da etapa de Leitura comunitária, quais sejam, senso de comunidade, expectativas e prioridades, categorizada no âmbito da gestão urbana (a ação do planejar) foram: (i) promover o encontro entre os futuros moradores, principalmente aqueles que farão divisa e morarão no mesmo quarteirão; (ii) levantar as expectativas e prioridades dos moradores quanto à convivência e ao compartilhamento e qualidade dos espaços urbanos públicos do loteamento; (iii) definir as prioridades e preferências dos moradores quanto ao tipo de equipamentos urbanos comunitários, de mobiliário urbano e de atividades de lazer, bem como o aspecto desejado para esses moradores.

\section{O PLANEJAMENTO URBANO NO BRASIL E O EMPODERAMENTO COMUNITÁRIO}

Algumas modificações ocorridas no início da década de 2000 na estrutura administrativa do governo federal, na legislação urbana e nas políticas públicas repercutiram na dinâmica urbana das cidades brasileiras. Tendo isso em vista, são destacados, a seguir, estes aspectos: (i) a historicidade da legislação do planejamento urbano, indo das modalidades excludentes dos planos diretores à aprovação do Estatuto da Cidade, que regulamenta o discurso da gestão democrática e gera um incremento na atuação dos movimentos populares na produção do espaço urbano; (ii) a implementação de políticas públicas, reunindo a legislação urbanística e os programas de financiamento que passaram a incluir entidades não governamentais como promotoras da regularização fundiária e da provisão de HIS.

Inicialmente, cumpre frisar que a atuação das entidades sem fins lucrativos na produção do espaço urbano e na provisão habitacional foi incrementada com a aprovação da lei federal denominada de Estatuto da Cidade (BRASIL, 2001), que regulamentou os artigos 182 e 183 da Constituição Federal (BRASIL, 1988). O estatuto, entre outros aspectos, afirmou a obrigatoriedade de planos diretores para cidades com mais de 20 mil habitantes ou que se encaixassem nas situações descritas no artigo 41 e facilitou a criação do Ministério das Cidades em 2003.

Os planos diretores começaram a se difundir na década de 1940, tendo recebido outras denominações a partir de 1960. Como Villaça (1999, p. 204) aponta, “o período de 1930-1990 pode ser dividido em três subperíodos: o do Urbanismo e do Plano Diretor (1930-1965), o dos Superplanos (1965-1971) e do "Plano sem mapa" (1971-1992)". Em tais períodos, os planos foram feitos, numa leitura geral, exclusivamente por profissionais, isto é, sem a participação comunitária, e, por isso, foram de difícil aplicação e geralmente engavetados (VILLAÇA, 1999).

Nos anos 1970, foi vivenciado o fortalecimento dos movimentos populares. De acordo com Villaça (1999, p. 231), já “nos anos de 1980, especialmente com a mobilização estimulada pelas possibilidades - embora limitadas - de influenciar na elaboração da nova Constituição do país, esses movimentos cresceram muito em organização, adesões e atuação".

No fim da década de 1980, a Constituição Federal avançou ao apresentar o Plano Diretor como um instrumento que definia se a propriedade urbana estava ou não cumprindo sua função social. Contudo tal previsão constitucional necessitava ainda de regulamentação, a qual foi alcançada somente em 2001, com a aprovação do Projeto de Lei do Senado n. 181/1989, conformando-se na Lei Federal n. 10.257, denominada, como dito, Estatuto da Cidade.

O cunho participativo que os planos diretores deveriam seguir foi exigido pelo Estatuto da Cidade, o que gerou novas dinâmicas de elaboração dessa legislação. Esse fato desencadeou, por exemplo, a descentralização dos saberes profissionais 
e do papel isolado do arquiteto e urbanista no planejar urbano e na produção do espaço (GRANT, 2015). Também abriu maior espaço para que as entidades sociais se reafirmassem e mostrassem atuação mais efetiva na requalificação dos espaços habitacionais ocupados ou de novos espaços urbanos, requeridos para suprir as demandas sociais por um lugar na cidade.

Assim, ao mesmo tempo, o papel centralizador do poder público e a onipotência dos profissionais da área do urbanismo abriram espaço para a gestão democrática e compartilhada (GRANT, 2015).

Esse caminho de gestão democrática e compartilhada tem resposta nas políticas públicas, com a criação dos programas de autogestão habitacional financiados pelo governo federal. Estes estiveram presentes nas reivindicações dos movimentos populares desde 1988, sendo que, em 1989, surgiram os primeiros programas. Em 2003, o movimento popular apresentou uma proposta de adaptação para o Programa de Arrendamento Residencial (PAR) no sentido de incluir a modalidade de autogestão. Entre 2006 e 2008, foi aprovado um projeto de lei que criou o Sistema Nacional de Habitação de Interesse Social (SNHIS), e, por meio do Fundo Nacional de Habitação de Interesse Social (FNHIS), foi aprovada uma lei que admitia o repasse de recursos diretamente às entidades. Em 2008, foi lançado o Programa Minha Casa Minha Vida (PMCMV), compreendendo um conjunto de programas habitacionais do governo federal, com diferentes fontes de recursos e faixas de renda atendidas.

Se a gestão democrática não é exercitada, o resultado normalmente não é satisfatório e traz mais problemas que soluções. Fazer planejamento sem contar com a opinião de quem vai ser de fato afetado pelas modificações, está, desde o início, condenado ao fracasso. É o caso da experiência ocorrida em São Paulo, durante a elaboração do plano diretor estratégico, que deveria contar com a participação do cidadão no processo de planejamento com o objetivo de ser uma forma de inclusão social para indivíduos que vivem à margem da sociedade. Entretanto provou-se impróprio e causou desapontamento e decepção aos participantes. O plano que ocorreu de portas fechadas e buscou a opinião pública de forma inconsistente, direcionando o questionamento para assuntos específicos e negligenciando a real necessidade da população. A prefeitura explicou tal abordagem afirmando que a população não estaria capacitada para opinar sobre a cidade como um todo, pois estariam preocupados apenas com seu entorno imediato, condena Torres (2009).

Em contrapartida, experiências que tomaram partido da colaboração e do empoderamento comunitário para a viabilização do projeto obtiveram sucesso, resultando num maior envolvimento das pessoas, aumento da qualidade de vida local e do sentimento de pertencimento da comunidade daquele espaço (SANOFF, 2007; CILLIERS; TIMMERMANS, 2014; MOORE; ELLIOTT, 2015). Isso faz com que a própria comunidade assuma a responsabilidade de manter o espaço urbano em ótimas condições.

Essas articulações sociais estão mudando a maneira tradicional de planejamento, utilizando práticas colaborativas que podem substituir as ações do estado, e obter resultados que antes não seriam possíveis, principalmente em situações conflituosas. É o início de uma nova era de políticas públicas voltadas para o cidadão, a fim de solucionar definitivamente os problemas sociais e urbanísticos que assolam as cidades e, quem sabe, o surgimento de um novo modelo de governo.

O uso de técnicas de planejamento estratégico aplicadas ao empoderamento de comunidades locais é uma alternativa para aumentar o espírito colaborativo e solidário entre as pessoas promovendo o bem-estar de todos, conferindo assim maior pertencimento e, muitas vezes, viabilizando requalificações urbanas por completo em bairros. 


\section{A TRAJETÓRIA DA AUTOGESTÃO EMPODERADA DO GRUPO DE MULHERES UNIDOS VENCEREMOS E AS CARACTERÍSTICAS DE IMPLANTAÇÃO DO LOTEAMENTO CANA ̃̃}

O Grupo de Mulheres Unidos Venceremos é uma entidade não governamental que desenvolve projetos sociais no bairro Leonardo Ilha, em Passo Fundo, Rio Grande do Sul, há mais de 10 anos. A principal ação dessa entidade de autogestão é a implantação do loteamento Canaã, em duas fases, totalizando a ocupação de uma área adquirida de $94.935,93 \mathrm{~m}^{2}$, com 210 lotes e 210 HIS (Figura 2). O contexto de construção desse loteamento e das habitações faz parte de um novo modo de operar e de solucionar os problemas urbanos, constituído com base na ideia de uma sociedade mais proativa, empoderada e independente do poder público.

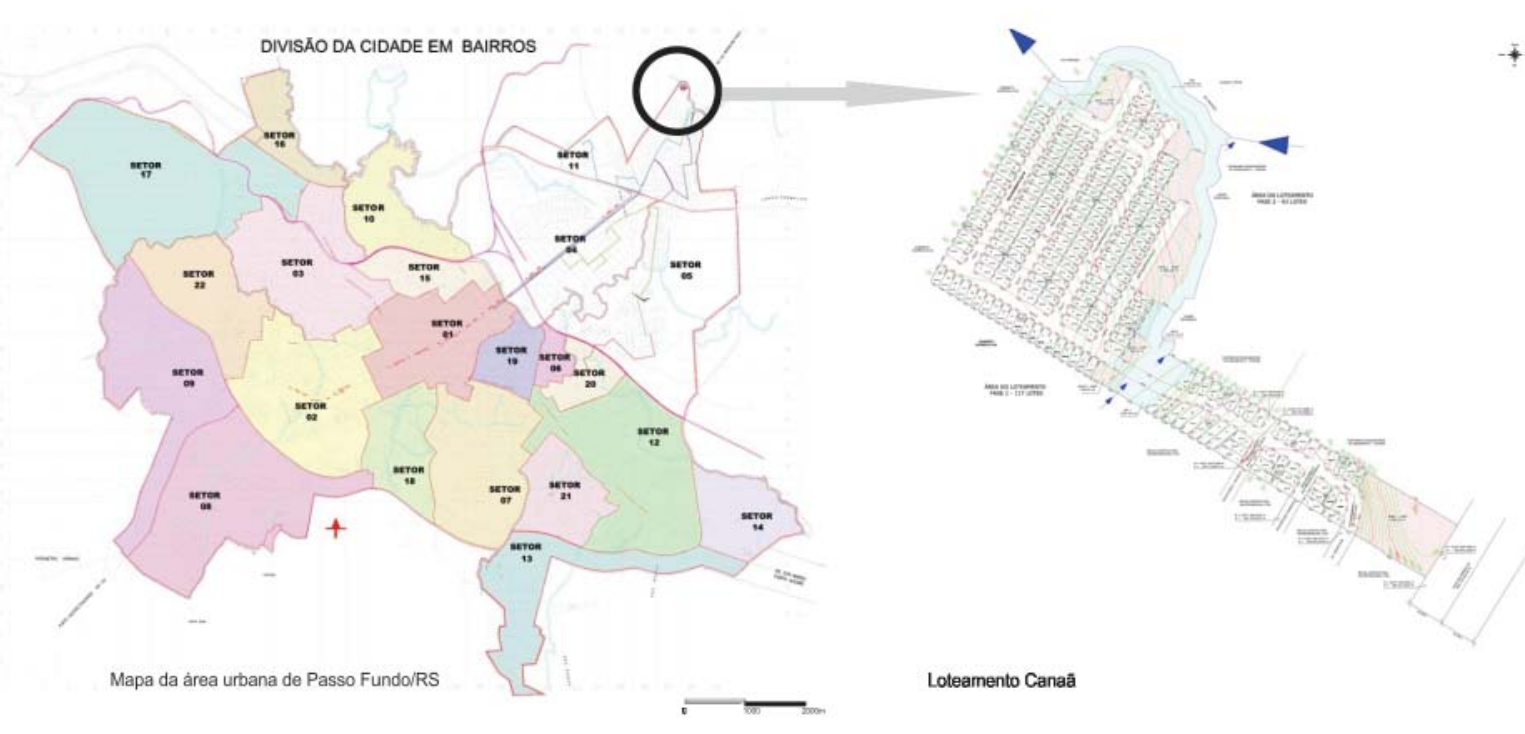

Figura 2 - Localização do futuro loteamento Canaã, Passo Fundo, RS, Brasil Fonte: Prefeitura Municipal de Passo Fundo, modificado pela autora (2015).

O termo empoderamento, tradução literal do inglês empowerment, é aqui entendido como reconhecimento do poder da sociedade de autogerir empreendimentos e de produzir o espaço. Historicamente, ele surgiu nos anos 1970, com vistas a dar destaque para a participação e para a organização comunitária, fazendo parte dos primeiros trabalhos que buscaram relacionar poder e pobreza. Seu caminho passa pela ideia de libertação das práticas sociais injustas e opressivas. Por esse pequeno histórico, nota-se que a conceituação do termo é complexa, estando fundada em distintas áreas do conheci- mento e com raízes nas lutas por direitos civis originadas nos países desenvolvidos no século XX (LIMA, 2008).

Nesse sentido, impulsionada a preencher uma lacuna deixada pelo Estado, uma forma de planejamento informal, realizada por atores sociais sem vínculos políticos ou institucionais, unidos por um objetivo comum, despertou-se na sociedade. A união da população local ocorreu no intuito de solucionar, de maneira imediata, o que, devido à burocracia e à falta de transparência das políticas públicas, levava muito tempo para ser feito. Normalmente, essas mobilizações são 
temporárias, movidas pela necessidade de agregar valor ao espaço e de tomar ações concretas para solucionar um problema específico (TORRES, 2009; DONG; ZHU, 2015). Essas redes podem contar, em determinados momentos, com a ajuda do governo ou de entidades privadas como facilitadores do processo, mas não como líderes.

O lançamento dos programas federais de financiamento habitacional favoreceu que o planejamento informal protagonizado por entidades sociais emergisse ainda mais, corroborou instrumentos legislativos como o Estatuto da Cidade e, ao mesmo tempo, exigiu a organização do planejamento urbano no nível municipal. Assim, foi requerida, por exemplo, a construção de planos diretores municipais fundamentados nos mecanismos já mencionados, a fim de que o município se tornasse apto a solicitar recursos financeiros em diversos campos de atuação. Foram abertos financiamentos exclusivos do PMCMV para entidades sociais sem fins lucrativos. Nesse contexto, $\mathrm{o}$ Grupo de Mulheres Unidos Venceremos se candidatou ao PMCMV na modalidade entidades, obtendo financiamento para provisão habitacional. Foi o primeiro grupo a ser contemplado nessa modalidade no país. A trajetória do Grupo de Mulheres Unidos Venceremos descrita na Figura 3, demonstra o engajamento da entidade para alcançar a implantação do loteamento Canaã.

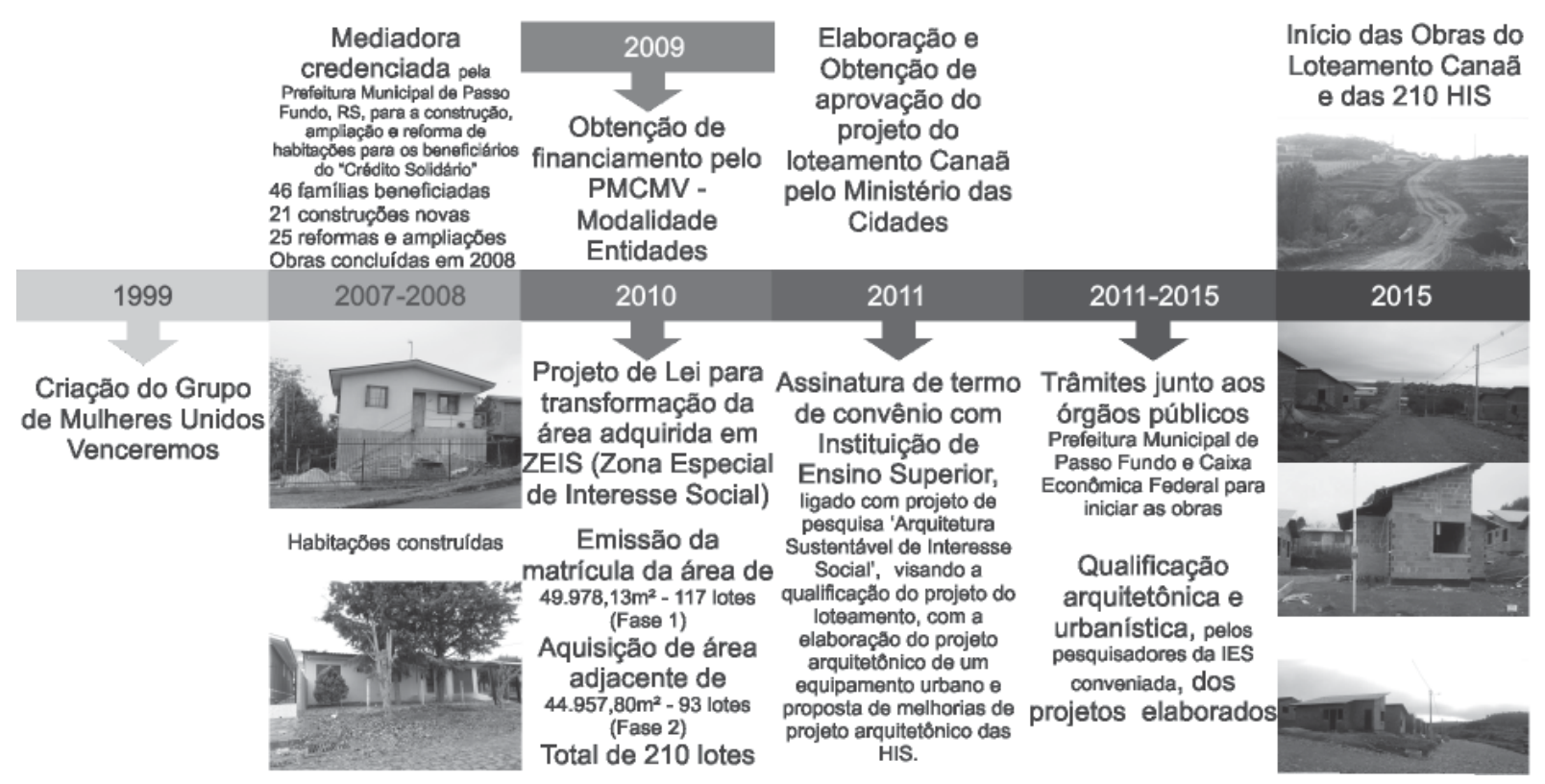

Figura 3 - Linha do tempo de atuação do Grupo de Mulheres Unidos Venceremos

O loteamento Canaã localiza-se num dos limites do perímetro urbano de Passo Fundo. O impacto que essa localização pode vir a gerar nas famílias que ali se assentarão talvez não seja tal alto, uma vez que a grande maioria de seus futuros moradores (63\%) é proveniente dos dois bairros vizinhos (Leonardo Ilha, 37\%, e São José, 26\%) ou de outras localidades periféricas da malha urbana.
O bairro Leonardo Ilha compreende uma extensão do bairro São José, e, por sua vez, o novo loteamento Canaã abrange uma extensão do bairro Leonardo Ilha. Dessa forma, percebe-se que muitos dos futuros moradores do novo loteamento têm conhecimento de seus arredores e dão preferência ao espaço físico de seu futuro bairro, já que estão a ele familiarizados, e também pela organização co- 
munitária que já favorece os dois bairros já existentes.

Apesar do impacto da localização do loteamento Canaã ter atenuantes, é inegável que um dos grandes problemas no processo de urbanização atual é a fragmentação do espaço urbano. Os bairros residenciais estão cada vez mais longe dos centros urbanos, onde se concentram os locais de trabalho e de lazer.

Essa condição de morar na periferia é entendida geralmente como algo inevitável, como menciona Carlos (2008, p. 134): “o homem vive onde ele pode morar, e onde pode morar será determinado pela renda que recebe e pelos sacrifícios que ele pode fazer". Por outro lado, Mattoso (2010, p. 38) compreende essa condição ou afastamento das facilidades urbanas, não como uma falta de outras oportunidades, mas sim uma opção feita pelo indivíduo, ao considerar que a expansão dos subúrbios no Rio de Janeiro, não foi necessariamente "através da força ou da autoridade da administração política, mas sim por ter optado por esta região, em muitos casos, pela acessibilidade aos terrenos e aluguéis mais baratos".

A segregação resultante desse modelo afeta a relação entre as pessoas reduzindo a possibilidade de convívio entre classes sociais distintas. Para Gonçalves (2002, p. 10) o abandono e o desequilíbrio da paisagem urbana brasileira ocorrem principalmente em decorrência da inatividade e da omissão do estado em desenvolver políticas que visem à superação da segregação das diferentes classes sociais. Resultando em muitos problemas de preconceito e violência, devido principalmente a essa clara separação entre as classes, a qualidade das habitações e dos espaços urbanos, e áreas de lazer são assim comprometidos. Enquanto nos bairros mais abastados os espaços de lazer se concentram dentro dos lotes privados e cercados por muros, nos bairros mais carentes, estes estão normalmente abandonados ou malcuidados. O medo de sair às ruas é um dos fatores que propiciam o acontecimento desses casos.

Tudo que acontece nas cidades é consequência dos seus moradores e da sociedade que as envolve. Segundo Park (1967, p. 34), através dos tempos, todo setor e quarteirão da cidade assume algo do caráter e das qualidades de seus habitantes. Portanto a segregação ou exclusão da população pobre ocorre por decorrência dos costumes já inerentes às pessoas. Porém deve ser compromisso da população e do governo desfazer esse conceito, e possibilitar o relacionamento entre a população. Uma maneira de possibilitar o relacionamento igualitário e o uso democrático do espaço público é investir em áreas abertas de qualidade para lazer e cultura. Para Magnoli (2006, p. 143) o espaço livre de edificação é o mais democrático dos espaços já que este está vinculado diretamente à paisagem, e deve ser considerado como elemento integrador entre a natureza e a cidade, além de ser de fundamental importância para as pessoas que as ocupam, ou circulam entre elas tanto como elemento de localização, como de ligação entre edifícios. São característicos por formar a base natural para a paisagem urbana.

Fica claro que os espaços públicos de lazer são importantes para toda a população, já a responsabilidade pela criação e manutenção dessas áreas é nebulosa. Os espaços públicos são elementos da paisagem urbana que pertencem ao governo. Sua manutenção deveria estar bem definida nas políticas públicas de governo, no entanto, devido ao fato de o poder público ser limitado e considerando que o empenho dele está em outras áreas como educação, saúde e moradia, a qualificação dos espaços abertos acaba sendo deixada de lado, resultando em perdas na qualidade urbana dos bairros. 


\section{METODOLOGIA}

As principais ações desenvolvidas pela IES para o Grupo de Mulheres Unidos Venceremos, a partir de convênio firmado em 2011, tem relação com pesquisa, dada sua vinculação ao projeto de pesquisa "Arquitetura Sustentável de Interesse Social", a provado por um órgão de fomento público, com a extensão, feita por intermédio do Escritório Modelo da IES, e com o ensino, em função da realização de algumas atividades aplicadas nas disciplinas de planejamento urbano e regional e de HIS. As principais atividades conduzidas foram: (i) aplicação de formulário com questões objetivas e entrevista semiestruturada a 150 das 210 famílias dos futuros moradores do loteamento Canaã, com o objetivo de traçar o perfil socioeconômico, definir suas preferências quanto a futuras ampliações das HIS e produzir tipologias habitacionais e urbanas; (ii) elaboração de um projeto arquitetônico das HIS, incorporando tanto a possibilidade futura de ampliações dimensionais, quanto um projeto de arquitetura de interiores; (iii) elaboração de projeto urbanístico para qualificar o sistema viário do futuro loteamento; (iv) elaboração do projeto do centro comunitário; (v) realização da atividade "Leitura comunitária: senso de comunidade, expectativas e prioridades", com 300 moradores das 210 famílias, a partir da qual se buscou reforçar o vínculo comunitário entre as famílias que irão morar no loteamento Canaã e sistematizar suas percepções e expectativas quanto ao espaço urbano compartilhado. Ao mesmo tempo, as dinâmicas tinham o objetivo de iniciar um processo de projeto colaborativo para a elaboração das propostas de equipamentos urbanos comunitários e de configuração dos espaços públicos, em especial os de lazer.

Nas atividades de leitura comunitária, retratada neste artigo, a metodologia foi composta de dinâmicas de participação comunitária e de planejamento/ projeto colaborativo (SANOFF, 2007; CILLIERS, TIMMERMANS, 2014), a fim de que fossem observados o senso de comunidade, as expectativas e as prioridades do público pesquisado.

A participação comunitária consistiu em estimular os moradores a assumirem o papel de protagonistas na construção do espaço coletivo do loteamento. Eles também foram motivados a externar seus anseios e receios, suas expectativas e preferências, criando, desse modo, um momento de troca de sensações e de compartilhamento de emoções na busca de congruências entre todos os futuros moradores, principalmente dos futuros vizinhos. A ideia era conferir um encontro que oportunizasse a manifestação de cada um deles, numa espécie de contraponto às reuniões tradicionais, nas quais eles normalmente participam como ouvintes e receptores de informações relacionadas à burocracia de implantação do loteamento, à infraestrutura geral do projeto e à construção das habitações, que é dependente de financiamento público.

A participação comunitária significa envolver aqueles que são afetados por uma determinada escolha no processo de tomada de decisão. Ela promove decisões sustentáveis, fornecendo aos participantes a informação que eles precisam para se envolverem de uma forma significativa, e é explicado aos participantes como a sua participação efetiva pode afetar uma decisão ${ }^{4}$.

Nessa atividade de leitura comunitária, foram realizadas três dinâmicas, a saber: (i) "Vamos nos Conhecer - Troca de Crachás"; (ii) "Basquete dos Desejos - O que queremos e o que não queremos para o bairro?"; e (iii) "Dotmocracy - O que poderemos ter no bairro?" Tais dinâmicas

\footnotetext{
${ }^{4}$ Definição de arquitetos da The American Institute of Architects (AIA) no Workshop internacional: O Processo de Assistência ao Projeto de Cidade, realizado em dezembro de 2014, em Porto Alegre, RS. Mais informações em: https:/ / www.youtube. com/watch? $v=$ DkiEWreNnWs
} 
foram mediadas por 40 acadêmicos de arquitetura e urbanismo, distribuídos em 10 grupos, a fim de que estes também fossem sensibilizados da importância de observar os anseios da sociedade e de construir propostas de projeto que resultassem em uma maior satisfação dos usuários no pós-ocupação. Como a experiência mostrou, isso aproxima o pensar do arquiteto e do urbanista das necessidades e dos desejos dos futuros usuários. E mais, propostas desse tipo instigam uma postura de empreendedorismo social nos profissionais, que, por vezes, passam a buscar parcerias privadas para a realização dos projetos, em especial os de configuração de espaços públicos abertos (LIMA et al., 2007).

Os 300 moradores entrevistados compõem as 210 famílias (futuras mora- doras do loteamento), cujo perfil socioeconômico foi traçado na primeira atividade de parceria da IES com a entidade. Os futuros moradores são principalmente mulheres $(71 \%)$, com Ensino Médio completo $(28 \%)$ ou Ensino Fundamental incompleto $(27 \%)$, possuem como renda familiar entre um e dois salários mínimos, entre 21 e 30 anos de idade (42\%) e sendo a maioria solteiros ou separados $(60 \%)$.

Na dinâmica 'Vamos nos Conhecer - Troca de Crachás' (Figura 4) todos os crachás foram recolhidos e colocados numa urna. Em seguida, cada participante pegava um crachá e escolhia a quem poderia pertencer, caso não fosse daquela pessoa, esta o repassava à pessoa correta e assim sucessivamente.

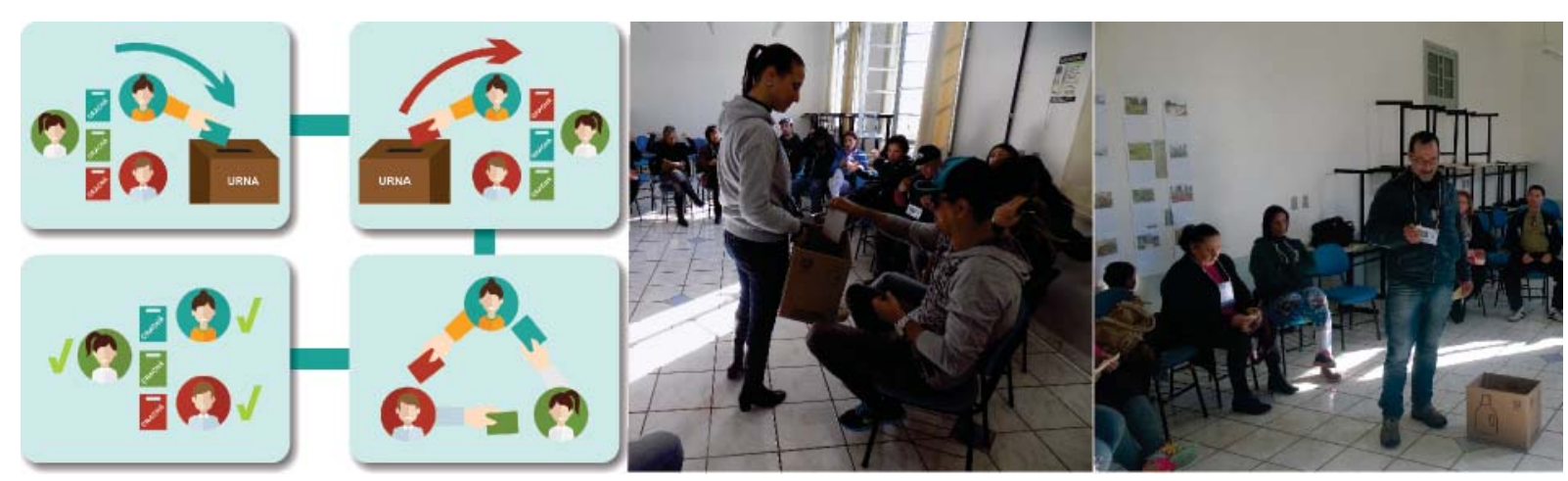

Figura 4 - Diagrama de funcionamento e fotos registro da dinâmica 'Vamos nos Conhecer - Troca de Crachás'

Na dinâmica 'Basquete dos Desejos - O que queremos e o que não queremos para o bairro?' (Figura 5) foi solicitado aos participantes que escrevessem algo que desejassem para o bairro e algo que não desejam para o bairro; o pedaço de papel com o que não desejam, deveria ser amassado e arremessado em um cesto. Foi orientado aos participantes a falar em voz alta o que não desejavam quando arremessavam; o pedaço de papel com o que desejavam deveria ser fixado no rolo de papel pardo; em seguida, os conteúdos apontados foram analisados e agrupados por afinidade de itens para que houvesse uma leitura clara do que é desejado. Do cesto, foi coletado uma amostra de 10 dos pedaços de papel que foram arremessados e que representavam algo que não queriam para o loteamento e fixados no papel pardo, agrupando-os por itens afins assim como na ação anterior. Para finalizar essa atividade, foi aberto um espaço para que cerca de cinco participantes comentassem sobre seus desejos. 


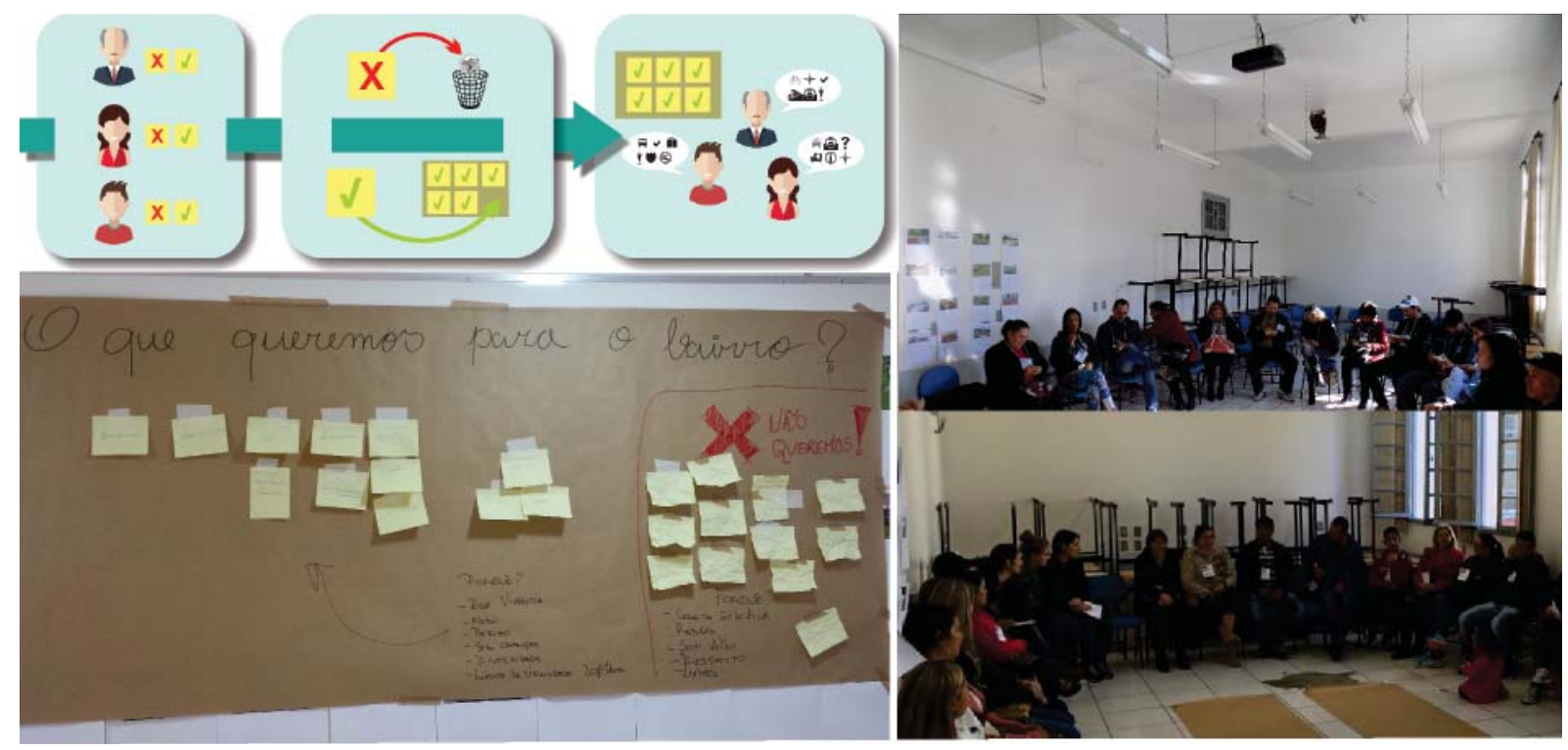

Figura 5 - Diagrama de funcionamento e fotos registro da dinâmica 'Basquete dos Desejos - O que queremos e o que não queremos para o bairro? '

A última dinâmica aplicada (Figura 6) foi denominada de 'Dotmocracy - O que poderemos ter no bairro? ' É uma ferramenta de pesquisa de preferências de imagens que contribuiu para definir as prioridades e preferências dos moradores quanto ao tipo de equipamentos urbanos comunitários, de mobiliário urbano e de atividades de lazer, bem como o aspecto desejado para esses moradores. Esse "método de pesquisa se baseia no registro individual das preferências quantitativas dos participantes em um formulário, os resultados são considerados justos e neutros, o que ajuda a gerar um consenso dentro da comunidade" (ANDERSON, 2013, p. 69).
Foram apresentadas aos moradores 4 imagens distribuídas em cada um dos seguintes temas: playground, ciclovia, horta comunitária, quadra poliesportiva, áreas verdes, academia pública, pista de skate, churrasqueiras, pomar, biblioteca, escola de educação infantil e posto de saúde, totalizando 48 imagens. Para cada imagem foi solicitado que assinalassem individualmente sim, talvez ou não, conforme a preferência.

Caso o participante não desejasse nenhuma das quatro propostas, deveria assinalar com um $\mathrm{X}$ em todas as propostas. Ao final da dinâmica, foram reservados 10 minutos para debate sobre a atividade. 


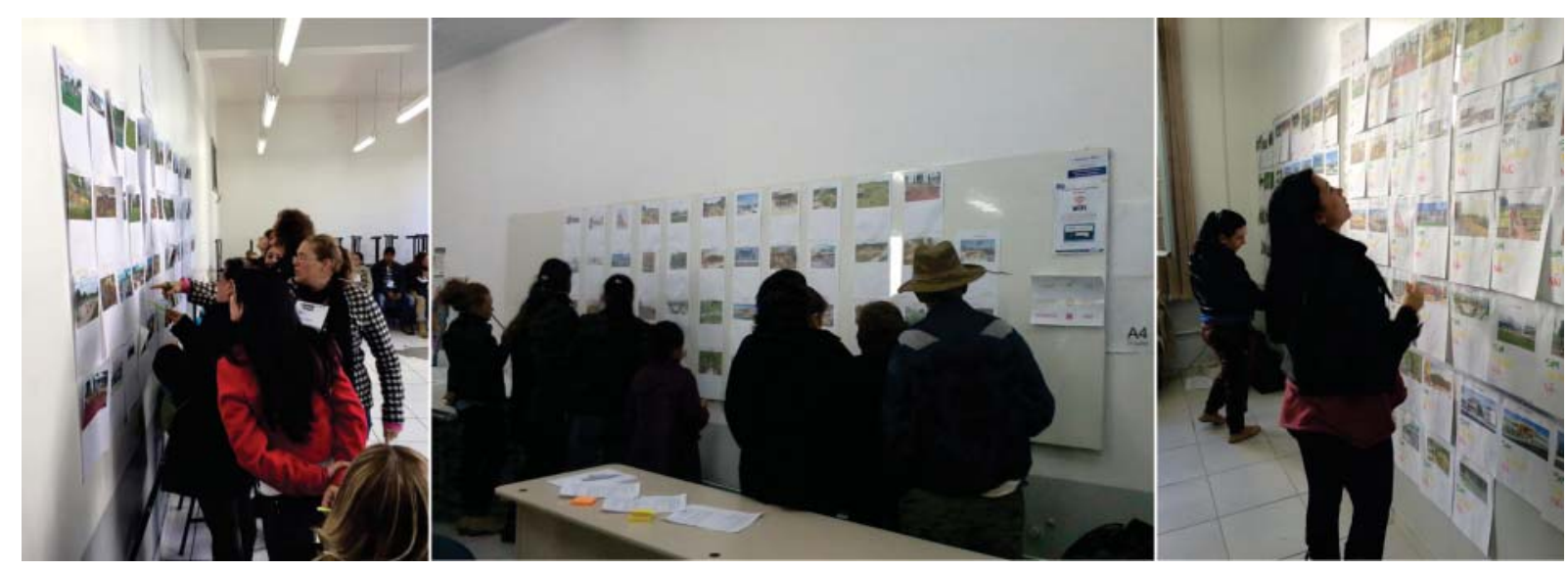

Figura 6 - Fotos registro dos moradores realizando a dinâmica 'Dotmocracy'

\section{RESULTADOS E DISCUSSÃO}

Na dinâmica "Basquete dos desejos - O que queremos para o bairro? ", em relação a sensações, os itens mais desejados para o loteamento foram, nesta ordem, tranquilidade $(27 \%)$, respeito $(26 \%)$, desenvolvimento (24\%) e companheirismo (11\%). Quanto a equipamentos urbanos comunitários e de infraestrutura, ficou evidente a necessidade de posto de saúde (30\%), escola de educação infantil (20\%), bem como a preocupação com a segurança (20\%). Vale pontuar que os entrevistados mencionavam que o bairro fica no extremo do perímetro urbano, afastado do centro da cidade, daí os índices elevados para os elementos supracitados.

No agrupamento daquilo que não querem, foi mencionado, quanto a situações indesejadas, bagunça e violência, com iguais $32 \%$, e grande receio com relação à instalação de bares. Quanto aos equipamentos, $38 \%$ dos entrevistados citaram rejeição à pista de skate, aspecto que foi relembrado na dinâmica "Dotmocracy - O que podemos ter no bairro?". Nesta, entre as imagens apresentadas para escolha, foram mais apontadas aquelas que se relacionavam a locais para atividades recreativas e de lazer, como playground $(83 \%)$, áreas verdes (76\%), academia ao ar livre (74\%), quadra poliesportiva (69\%), ciclovia $(67 \%)$ e pomar $(64 \%)$.
Dentre as imagens apresentadas aos participantes, uma das imagens de áreas verdes obteve $76 \%$ de sim, a de posto de saúde obteve $92 \%$ de sim, a de ciclovia, $67 \%$ assinalaram sim, a de playground $83 \%$ assinalaram sim, enquanto a de pista de skate, houve uma rejeição de $64 \%$. Os moradores apontaram a pista de skate como uma atividade que agradaria somente alguns e traria problemas quanto ao incentivo ao uso de drogas. Os participantes acham mais interessante a construção de áreas verdes, praças e academias ao ar livre, que possibilite o convívio entre pessoas de todas as faixas etárias. Uma das imagens de horta comunitária obteve $65 \%$ de sim, indicando hortas verticais mais compactas e ocupando menor espaço em contraponto a imagens de hortas comunitárias em espaços maiores e abertos, ocupados horizontalmente. Em uma das imagens de biblioteca, 61\% assinalaram sim, e $15 \%$, talvez. Entre as imagens de academia pública, para uma delas, $74 \%$ assinalaram sim. Enquanto que, para uma das imagens de escola de educação infantil, $84 \%$ assinalaram sim. Para uma das imagens de pomar, $64 \%$ assinalaram sim. Para uma das imagens de quadra poliesportiva, 69\% assinalaram sim e, para uma das imagens de quiosque, $56 \%$ assinalaram sim. 


\section{CONSIDERAÇÕES FINAIS}

Os resultados e os comentários ${ }^{5}$ dos participantes pós-encontro mostraram que técnicas de participação comunitária aplicadas na leitura comunitária realmente aproximam as pessoas e favorecem o efetivo aumento dos vínculos entre elas.

Na dinâmica "Vamos nos Conhecer - Troca de Crachás", os futuros moradores puderam conhecer melhor uns aos outros e perceber os vizinhos que terão no loteamento Canaã. Houve, inclusive, o entendimento e uma combinação acerca de questões como construção de muros, grades, divisas, dentre outros detalhes implicados no direito de vizinhança.

Na dinâmica 'Basquete dos Desejos - O que queremos para o bairro?' Foram perceptíveis os pensamentos sobre o que desejam e/ou não desejam quando estiverem habitando o loteamento, muitos apontaram o desejo por um lugar para descansar, sem badernas, com respeito.

Na última dinâmica 'Dotmocracy - O que podemos ter no bairro?' Enquanto os futuros moradores votavam, muitos debatiam as ideias, muitos votaram mais por escolas, posto de saúde, mercados, equipamentos esses que são inexistentes próximo ao loteamento, priorizando mais a necessidade diária e rotineira, ao invés do lazer.

A maioria das pessoas inseridas em cada um dos grupos pelo critério da vizinhança em sua quadra não se conhecia. A atividade proposta permitiu que fosse "quebrado o gelo" e houvesse uma maior interação entre os moradores. Estes foram, assim, integrando-se e explorando a futura vizinhança. Na ocasião, também foi solicitado que eles expusessem a profissão, o local de moradia atual e que falassem

\footnotetext{
${ }^{5}$ Comentários dos futuros moradores no final das dinâmicas: "Eu acho que foi bom pra gente ter uma noção do que pode ter no loteamento que vamos morar, que vamos morar logo"; "Para mim, foi legal, pois conseguimos nos conhecer e interagir".
}

sobre suas famílias, no intuito de gerar afinidades e interesses em comum, assim como possíveis amizades.

No geral, os grupos foram bem participativos em todas as atividades, os conflitos gerados em torno das preferências de alguns dos moradores foram discutidos e resolvidos rapidamente. A dinâmica que mais gerou dúvidas foi a última, tendo em vista o fato de que os futuros moradores mostravam-se incrédulos a respeito da efetiva realização dos projetos apresentados.

Foi possível perceber, pelo comportamento dos futuros moradores, que o loteamento é o sonho da vida deles e que estão batalhando para conquistá-lo, daí estarem ansiosos pela entrega das moradias.

Os projetos de planejamento estratégico, sejam voltados ao planejamento urbano, ou para outros modelos, podem ser executados de maneiras variadas, e ter origem na iniciativa pública ou privada, mas, para terem êxito, devem dispor muito tempo para ouvir a opinião da população. Exemplos em que a opinião pública foi deixada de lado, negligenciada ou mesmo desrespeitada, resultaram em falhas diversas, e desapontamento.

Projetos colaborativos nos quais a população pode ser ouvida, e sua opinião contou para o resultado efetivo, geraram maior entrosamento da comunidade com o projeto e o sentimento de pertencimento foi desenvolvido. Isso faz com que a população sinta que o empreendimento é pensado para solucionar seus problemas, a aceitação pública é maior.

As redes de colaboração são o futuro do planejamento estratégico, permitem o envolvimento e a opinião de todas as pessoas que serão atingidas pelo projeto, funcionam de forma não linear e não hierárquica, podem ser aplicadas a diversas situações que necessitem mudanças.

Com essas colocações podemos perceber que o planejamento estratégico 
efetivo precisa contar com a opinião pública e dar à comunidade a oportunidade de colaborar com o projeto. A audição pública, e o diálogo nesse quesito, é tanto ou muito mais importante que a vontade governamental de fazer mudanças acontecerem na cidade.

O ganho observado, no caso analisado, foi o progresso no processo de autogestão habitacional. Os beneficiários, com as dinâmicas de leitura empregadas, tornaram-se mais proativos e participativos nas decisões do projeto.

Os desdobramentos das ações retratadas neste artigo caminham para reforçar o vínculo comunitário e a participação efetiva dos futuros moradores do loteamento Canaã nas decisões e no gerenciamento da localidade pós-ocupação, bem como para a posterior elaboração de projetos colaborativos dos espaços públicos abertos voltados para o lazer e para a implantação de equipamentos urbanos comunitários no loteamento.

\section{REFERÊNCIAS}

ANDERSON, Christina. Registrando a preferência da comunidade por forma e sustentabilidade: Pesquisa de Preferências de Imagens (IPS). In: FARR, Douglas. Urbanismo sustentável: desenho urbano com a natureza. Tradução: Alexandre Salvaterra. Porto Alegre, RS: Bookman, 2013.

BRASIL. Estatuto da Cidade: Lei 10.257/2001 que estabelece diretrizes gerais da política urbana. Brasília: Câmara dos Deputados, 2001.

BRASIL. Constituição (1988). Constituição da República Federativa do Brasil. Brasília: Senado Federal, 1988.

CARLOS, Ana Fani Alessandri. A (re)produção do espaço urbano. São Paulo: Edusp, 2008.

CILLIERS, Elizelle J.; TIMMERMANS, Wim. The importance of creative participatory planning in the public place-making process. Environment and Planning B: Planning and Design, v. 41, n. 3, p. 413-429, jun. 2014. http:/ / dx.doi.org/10.1068/b39098
DONG, H.; ZHU, P. Smart growth in two contrastive metropolitan areas: A comparison between Portland and Los Angeles. Urban Studies, v. 52, n. 4, p. 775-792, jan. 2015.

GONÇALVES, Fábio Mariz. Discussões sobre o papel dos espaços livres públicos nos bairros de elite contemporâneos. Paisagem Urbana, São Paulo, n. 15, p. 9-33, dez. 2002.

GRANT, R. Sustainable African urban futures: stocktaking and critical reflection on proposed urban projects. American Behavioral Scientist, v. 59, n. 3, p. 294-310, mar. 2015.

KATZ, P. The new urbanism, toward an architecture of community. Nova York: McGrawHill, 1994.

LIMA, Catharina; QUEIROGA, Eugenio Fernandes; GONÇALVES, Paulo Cássio. Processos participativos e universidade. Balanço de uma experiência em disciplina de paisagismo. Paisagem Ambiente: ensaios, São Paulo, n. 24, 2007.

LIMA, Reinaldo dos Santos. Os desafios da responsabilidade social empresarial na relação com o empowerment comunitário: um estudo de caso da favela do Jardim Colombo, na cidade de São Paulo. 2008. Dissertação (Mestrado em Educação) - Faculdade de Educação, Universidade Estadual de Campinas, Campinas, SP, 2008.

MAGNOLI, Miranda Martinelli. Em busca de "outros" espaços livres de edificação. Paisagem Ambiente: ensaios, São Paulo, n. 21, p. 141-174, 2006.

MARICATO, E. Por um novo enfoque teórico na pesquisa sobre habitação. Cadernos Metrópole, São Paulo, n. 21, p. 33-52, $1^{\circ}$ sem. 2009. http://dx.doi.org/10.1590/5954

MATTOSO, Rafael. Um novo olhar sobre os entornos da cidade. Revista da FAU UFRJ, Subúrbios Cariocas, Rio de Janeiro, n. 2, p. 3638, 2010.

MAWROMATIS, Constantino. Tensiones y convergencia: el diseño urbano contemporáneo como alternativa a la ciudad dispersa y difusa. Revista Invi, v. 28, n. 79, p.125-163, 30 nov. 2013. http://dx.doi.org/10.4067/s071883582013000300005

MOORE, Kristen R.; ELLIOTT, Timothy J. From Participatory Design to a 
Listening infrastructure: a case of urban planning and participation. Journal of Business and Technical Communication, v. 30, n. 1. p. 1-26, out. 2015. http://dx.doi. org/10.1177/1050651915602294

NOVAK, Hélio. Os outros nomes do urbanismo: planejamento, projeto e desenho urbanos. Cadernos de Arquitetura e Urbanismo, Belo Horizonte, v. 13, n. 14, p. 127-146, dez. 2006.

PARK, Robert Ezra. A cidade: sugestões para a investigação do comportamento humano no meio urbano. Tradução de Sérgio Magalhães santeiro. In: VELHO, Otávio Guilherme (Org.). O fenômeno urbano. Rio de Janeiro: Zahar, 1967.
SANOFF, Henry. Participatory design. Design Studies, v. 28, n.3, p. 213-215, maio 2007. http:/ / dx.doi.org/10.1016/j.destud.2007.02.001

TORRES, Nilton Ricoy. Planejamento numa sociedade em rede. Práticas de planejamento colaborativo no Brasil. Cadernos Metrópole, São Paulo, v. 11, n. 22, p. 571-591, jul./dez. 2009.

VILLAÇA, Flávio. Uma contribuição para a história do planejamento urbano no Brasil. In: DEÁK, Csaba; SCHIFFER, Sueli Terezinha Ramos (Org.). O processo de urbanização no Brasil. São Paulo: Editora da Universidade de São Paulo, 1999. p. 170-243.

\section{Sobre a autora:}

Andréa Quadrado Mussi: Professora e Pesquisadora do Programa de Pós-Graduação Stricto Sensu em Arquitetura e Urbanismo da Escola de Arquitetura e Urbanismo da IMED - PPGARQ-IMED. E-mail: andrea@imed.edu.br 